\title{
STAKEHOLDER MAP OF THE MUSEUM OF VOJVODINA IN NOVI SAD
}

\author{
Olga Hadžić1, \\ Milena Nedeljković Knežević \\ ${ }^{1}$ Serbian Academy of Science and Arts, \\ Belgrade, Serbia \\ ¿University of Novi Sad, \\ Novi Sad, Serbia
}

\begin{abstract}
:
Stakeholder analysis is a useful tool for strategic planning of an organization and in this paper we will conduct the stakeholder analysis and stakeholder mapping for the Museum of Vojvodina in Novi Sad, which is one of the most popular attractions among cultural tourists visiting Novi Sad. The analysis of the tourist potential of the Museum of Vojvodina based on the opinions of the members of the focus group (experts from culture and tourism sectors) will be presented here.
\end{abstract}

Keywords:

Cultural tourism, stakeholders analysis, tourists, market attractiveness

\section{INTRODUCTION}

Cultural tourism is defined as visits performed by the people from outside the host community motivated wholly or in part by interest in historical, artistic, and scientific or lifestyle/heritage offerings of the host community, region, group or institution (McKercher \& Du Cros, 2015). Museums are important cultural attractions which attract many cultural tourists. Museum audiences have a strong link to tourism, since tourists are part of the audiences and for some museums even a larger portion of the total number of visitors (Black, 2002). Every museum has a long list of partners (stakeholders). Among the partners there are friends, supporters, sponsors, schools, arts organizations, media, libraries, business clubs and social clubs, community centres, colleges and universities. These are the people, groups, constituencies, and institutions that are likely to affect or be affected by a museum, its plans, or projects (Freeman,1984; Donaldson \& Preston, 1995; Hadžić et al., 2005).

"The Museum of Vojvodina is one of the oldest and richest museums in Serbia, housing collections of archaeology, history, history of art, and ethnology, with nearly 500,000 original objects. The scientifically complex permanent exhibition presents the development of the human kind in the present territory of Vojvodina, comprising the period of 8,000 years. On 3,000 square meters there are 6,000 objects which represent archaeology, general history, art history and ethnology. The permanent exhibition gives a synthesis of the region's several millennia long history. The exhibited objects are witnesses of human
Correspondence:

Olga Hadžić

e-mail:

ohadzic@dmi.uns.ac.rs 
communities and cultures in the Palaeolithic and Mesolithic periods; the first human traces nearly 70,000 years old in the vicinity of Irig; the Neolithic cultures at Starčevo, Vinča and other Neolithic cultures; the multilayered Gomolava, Feudvar and Kalkača; the mythic ages of the Ancient Greece and gorgeous monuments of the Roman Empire; the migration of people prior to their settlements and ethnic communities: Slovenes, Hungarians, Serbs and other nations (Museum of Vojvodina, 2017)".

\section{METHODOLOGY}

\section{Research problems}

1. Does the Museum of Vojvodina possess a high level of market attractiveness?

2. What is the stakeholder map of the Museum of Vojvodina?

\section{Sample}

Our sample consists of 30 experts from the field of culture and arts, history, archeology and ethnology and 20 stakeholders from the stakeholders map of the Museum of Vojvodina.

\section{Instrument}

For the purpose of the study we use the following set of indicators for the evaluation of market attractiveness of museums which are accommodated from Du Cros model (Du Cros, 2000). We remove the robustness concern from the model (fragility, impact of increased visitation) since it conflicts with market appeal from one side and from the other side fragility is very small for a museum similar to the museum of Vojvodina, and so it was neglected in this study.

- Ambience.

- The important national symbol.

- Possibilities for storytelling.

- The possibility of the formation of attractive cultural routes which include the Museum.

- The degree of differentiation of the Museum with respect to the surrounding cultural assets.

- Importance of the Museum for cultural education of members of the local community.

- Complementarity of Museum with other cultural tourism products at the destination.

- Influence of the Museum on the cultural development of the destination.

- Scientific research value of the Museum.

- The representativeness of the Museum for the tourism destination.

Values of the indicators are measured by experts from the sample with one of the following numbers: 1-low value, 2 -medium value, 3 -high value.

\section{RESULTS}

Ambience: The building of the Museum of Vojvodina is one of the most beautiful and representative buildings from the past of the city of Novi Sad. Located in an excellent location, directly across the Danube Park, the building attracts the attention of many visitors of Novi Sad, and it is particularly important for tourists who cruise the Danube and visit Novi Sad $(2,2)$.

National symbol: The Museum of Vojvodina is an important national symbol because it contains important museum fund that represents historical and social development of the people who lived in Vojvodina for a 
long time, and their mutual influence and interpenetration. In this way, the Museum of Vojvodina contributes to the preservation of multiculturalism and mutual respect of all national communities living in this area $(2,5)$.

Possibilities for story telling: The richness of the museum fund offers educated interpreters an opportunity for very interesting and diverse stories of the past times, archaeological remains, product development, historical events, famous people who lived and worked on the territory of Vojvodina and folk customs of ethnic communities $(2,6)$.

The possibility of the formation of attractive cultural routes which include the Museum of Vojvodina: Access to other cultural assets at the destination is excellent, because the cultural heritage Museum of Vojvodina is located in the old part of town, where also most of the important cultural assets of Novi Sad are located. In the immediate vicinity of the Museum of Vojvodina there is the Art Collection, as a part of the City Museum of Novi Sad. These two cultural institutions form the cultural cluster, which along with other cultural assets, especially the galleries on the Gallery Square, allows the formation of attractive cultural routes $(2,7)$.

The degree of differentiation of the Museum of Vojvodina with respect to the surrounding cultural assets: In Vojvodina museum institutions similar to the Museum of Vojvodina do not exist and that fact is an important element for the attractiveness of this museum $(2,8)$.

Importance of the Museum of Vojvodina for cultural education of members of the local community: The Museum of Vojvodina occupies an important position in the cultural life of Novi Sad and therefore the local community is an important promoter of this museum and important stakeholder of all museums. "Besides the permanent exhibition, the museum organizes exhibitions on certain topics - thematic exhibitions - exhibiting its own collections, as well as guest exhibitions from other national and foreign museums. The Department of History features the Collection of Applied and Visual Art with collections of period furniture, clocks and pictures, silverware, glass, porcelain, faience and women's handicraft. Collections of visual arts have been formed: the collections of paintings, prints, sculptures, tapestries and mosaics with numerous unique items. Employees at the Museum facilitate the variety of market segments to meet their educational needs" (Museum of Vojvodina, 2017).

Exceptional educational services of the Museum of Vojvodina help in establishing cooperation with many educational institutions including the University of Novi Sad. Now, the wider local community demonstrates the growing interest for the museum fund, as well as for cultural events that take place in the museu $(2,6)$.

Complementarity of the Museum of Vojvodina with other cultural tourism products at destination: The Museum of Vojvodina is one of those cultural assets that are almost unavoidable in the tourist offer of Novi Sad, especially aimed at those tourists who are interested in the culture of this area $(2,6)$.

Influence of the Museum of Vojvodina on the cultural development of Novi Sad: The Museum of Vojvodina has become one of those places in cultural life of the city in which numerous creators from various fields of science and art are gathered, contributing significantly to the local cultural development. Museum in the best possible way manifests now increasingly accepted opinion that a museum should be a dynamic institution, which performs an educational, scientific or broader social role and gathers community members around interesting cultural projects $(2,8)$.

Scientific research value of the museum: Experts from the museology highly evaluated scientific research value of the museum, because the fund of the Museum provides excellent conditions for scientists and students, studying the rich museum collection in the field of archaeology, ethnology, history, art history, zoology, botany, geology-paleontology and mineralogy-petrography, for necessary scientific research $(2,6)$.

The representativeness of the Museum for Novi Sad as a tourist destination: Assessment of the representativeness of the Museum is high because the fund of the Museum represents the development of the society on the whole territory of Vojvodina, and by doing so also allows the consideration of wider social processes that are connected with the development of Novi Sad as a tourist destination $(2,6)$.

All of the above indicators are highly assessed from the members of the sample and the conclusion is that the Museum of Vojvodina possess a high level of market attractiveness. 
Students of the Universities in Serbia: The following tasks for the improvement of the cooperation between Museum of Vojvodina and Universities in Serbia can be stated in the following way (Stanisavljević, 1995-1996):

- establish the habit of the use of the cultural content at the Museum from the point of view of the student population,

- determine the way of the visit to the Museum,

- determine the motivational aspect of the visit,

- determine the interest of students for the content of museum activities in order to implement the curriculum,

- determine the opinions of students about the type of the activities in the Museum in order to innovate the cooperation,

- determine student enrolment for museum contents activity to meet the needs for self education independently of the curriculum (personal interest and affinity).

These tasks are in full compliance with the latest trends in tourism, which is characterized by the desire of tourists to take part in creative activities during their stay at the destination, and it is one of the reasons for the increasing interest in volunteer tourism. One of the students' suggestions is that in order to significantly improve the image of the museum in relation to the student population it would be necessary to organize a large number of lectures on general culture and cultural history by prominent experts, expand the possibilities for the use of the library of the Museum, exchange of artefacts for the purposes of teaching, promote the works of professors and students, and organize various knowledge quizzes.

Schools in Serbia: The Museum of Vojvodina has an excellent educational service and its various and numerous activities in the local community have been recognised. However, to achieve greater involvement of schools in the field of cooperation with the Museum of Vojvodina it would be helpful to achieve even better results, attract the museum audience from schools, which would have the habit of visiting museums, both in Novi Sad, and when they visit other destinations.

Tourism sector: The partnership with the tourism sector, especially with travel agencies in Novi Sad and Belgrade, the Tourist Information Centre of Novi Sad and hotels in Novi Sad, which are important referral market for the Museum of Vojvodina, is of crucial importance for the promotion of the museum on the tourist market, and therefore employees of the Museum of Vojvodina should be engaged in order to improve these stakeholder connections. Often, tourism agencies possess the means and/or the expertise to assist cultural attractions in putting together packages and in understanding their potential tourist market. Cultural attractions and local tourism agencies can and must become true partners in realizing a community's heritage tourism potential.

Event organizers: Event tourism in Novi Sad in recent years is becoming increasingly important type of tourism and numerous visitors of the Museum of Vojvodina, including several thousand tourists, represent a potential market segment for the cultural product of the Museum of Vojvodina. Therefore, stakeholder relationships with the organizers of musical and other events are among the primary links, which should be developed, through the presence of a hyperlink on the Museum of Vojvodina at the websites of the event organizers and offering their visitors special discount for the tickets to the Museum of Vojvodina, Since fairs that are organized at the Novi Sad Fair are among the most visited events held in Novi Sad, development of the stakeholder relationship with the management of the Novi Sad Fair Master Centre, which is located near the fair ground, can significantly contribute to the development of cultural tourism in Novi Sad.

Printed and electronic media: Cooperation with the media is also very important, especially from the electronic media that have high ratings, such as TV Novi Sad, TV Panonija and TV Apolo. Continuous communication with the spectators of cultural blocks in the news broadcasts of the television on the activities of the Museum of Vojvodina, a special thematic exhibitions, concerts and other cultural events contribute to the formation of the image of this cultural institution as an institution of great importance to local cultural development of Novi Sad and the development of cultural tourism in this city. Information on permanent display 
but also thematic exhibitions and other important cultural events organized in the Museum of Vojvodina should be accessible to potential visitors-tourists through print publications and CDs, and a sufficient number of them have to be printed for the representatives of the tourism sector.

Cultural sector: Cooperation with other cultural institutions, in particular the Novi Sad City Museum and Galleries on the Gallery Square, in marketing and management expertise would be an important step in obtaining the status of Novi Sad as a "region that teaches" and in this direction it would be necessary to organize joint teams to work on the development of this concept, already very present in the development of European tourism.

Staff of the Museum of Vojvodina: Management of the human resources in the Museum of Vojvodina faces a number of problems including:

- Very demanding work, due to expectations of visitors that employees who are with them in the direct contact, have to be always friendly, helpful and willing to answer all questions.

- Employees of the Museum of Vojvodina do not have a clear perspective of advancement in the hierarchy, and because of that it is sometimes difficult to grip very qualified people.

- The absence of the Department of Human Resource Management is the practice of many organizations in the sector attraction. This has the effect that members of the top management who are not familiar with the methods of human resource development, do not develop such an organizational culture in which all employees participate in the formulation of the vision, mission and goals of the organization, and with the implementation of plans with a clear picture of their own role in this process.

- Seasonality, which is very present in the attractions work sector, does not encourage employees to be trained, that especially applies to employees with part-time and volunteers, who are numerous in many parts of the sector attraction.

Visitors of the Museum of Vojvodina: Museum visitors are important stakeholders and thus it is necessary to carry out continuous research on their assessment of the quality of the museum collection as well as performers (interpreters) who are in direct contact with the visitors, but also on the importance they attach to certain aspects of attractiveness of the museum. That would allow the formation of importance/performance matrix which has to bring attention to those sub-indicators where it is necessary to carry out improvements. For example, those sub-indicators which are poor valued with respect to the performance but highly valued with respect to the importance have to be seriously analyzed by the management.

Residents: Community support and involvement (for both human and financial resources) can greatly contribute to overall success of a cultural tourism product including that offered by the Museum of Vojvodina. Community can be a strong ally in reaching the tourist market, by generating positive word of mouth, influencing the choices of visiting friends and relatives, and offering complementary services or products.

Figure 1. Stakeholder Map of the main stakeholders of the Museum of Vojvodina (made by the authors)

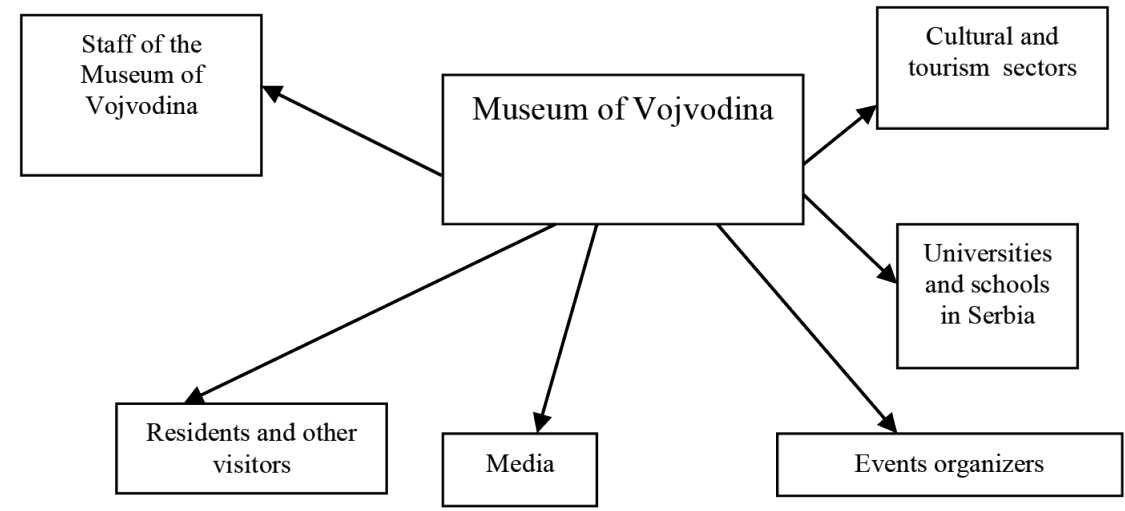


After open interviews with 20 stakeholders included in the stakeholders map of the Museum of Vojvodina we assessed the management plan of the Museum of Vojvodina. Management plan of the Museum has to be improved. In addition to planning the continuation of current activities of the Museum Management it is also necessary to improve the stakeholders relationships especially

1. employ a cultural manager,

2. improve public relations,

3. establish even stronger links with educational institutions,

4. improve connections with the tourism sector,

5. perform the market analysis and identify new market segments which might be interested for the museums product,

6. more actively attend international fairs in the field of tourism.

\section{CONCLUSION}

In this paper we established a map of the stakeholder relations of the Museum of Vojvodina which shows those stakeholder relationships, which we consider to be of the primary importance for the formation of a complex product in the cultural tourism of Novi Sad. As an important step in the process of the evaluation of the tourist attractiveness of the Museum of Vojvodina, we utilised the opinions of the members of the focus group and they highly estimated all indicators. It would be useful in the next step to include the perceptions of the tourists-visitors of the Museum of Vojvodina. Then we will be able to construct a more general model for the evaluation of the Museum of Vojvodina where all opinions have to be taken into consideration.

\section{REFERENCES}

Black, G. (2005). The Engaging Museum: Developing Museums for Visitor Involvement. Abingdon: Routledge.

Donaldson, Th., \& Preston, L. E. (1995). The Stakeholder Theory of the Corporation: Concepts, Evidence, and Implications. The Academy of Management Review, 20(1), 65-91.

Du Cros, H. (2000). Planning for Sustainable Cultural Heritage Tourism in Hong Kong. Final Report to the Lord Wilson Heritage Trust Council. SAR.

Freeman, E.R. (1984). Strategic Management: A Stakeholder Approach. Boston: Pitman.

Hadžić, O., Stojaković, G., Herman-Milinković, K., \& Ivanović, I. (2005). Kulturni turizam. Novi Sad: Prirodnomatematički fakultet u Novom Sadu, Departman za geografiju, turizam i hotelijerstvo.

McKercher, B., \& Du Cros, H. (2015). Cultural Tourism (second edition). London and New York: Routledge,

Museum of Vojvodina. (2017). About Museum - From Serbian National Collection to the Museum of Vojvodina. Retrieved August 2018, from https://www.muzejvojvodine.org.rs/index.php/eng/events/963-fromserbian-national-collection-to-the-museum-of-vojvodina

Stanisavljević, V. (1995-1996). Saradnja Muzeja Vojvodine i Univerziteta u Novom Sadu, Rad Muzeja Vojvodine (37-38), 281-291. 